\title{
Research Paper: The Immediate Effect of High Power Laser on Quadriceps Muscle Performance in Male Football Players: A Single-Group, Pretest-Posttest Trial
}

\author{
Elham Gorji ${ }^{1}$ (D), Seyed Mohsen Mir ${ }^{1 *}$ (D), Siamak Bashardoust Tajali' ${ }^{1}$, Kazem Malmir ${ }^{1}$ (iD
}

1. Department of Physiotherapy, School of Rehabilitation, Tehran University of Medical Sciences, Tehran, Iran.

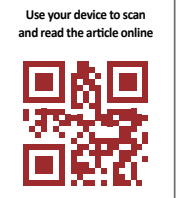

Citation: Gorji E, Mir SM, Bashardoust Tajali S, Malmir K. The Immediate Effect of High Power Laser on Quadriceps Muscle Performance in Male Football Players: A Single-Group, Pretest-Posttest Trial. Journal of Modern Rehabilitation. 2020; 15(1):7-14. http://dx.doi.org/10.32598/JMR.15.1.2

d. $)^{\circ}$ http://dx.doi.org/10.32598/JMR.15.1.2

Article info:

Received: 08 Sep 2020

Accepted: 19 Sep 2020

Available Online: 01 Jan 2021

Keywords:

Laser therapy, Athletic performances, Quadriceps muscles, Football

\section{ABSTRACT}

Introduction: The use of High Power Laser (HPL) has recently been emphasized in physiotherapy. Previous studies suggest that the prophylactic use of laser has ergogenic effects on athletic performance by increasing the contractile function of skeletal muscles. Recently, muscle function improvement is a new research idea in the field of laser therapy. Based on our knowledge, there are only two studies on the effects of HPL on muscle performance although with contradictory results. The purpose of this study was to investigate the effects of HPL on quadriceps muscle performance in male football players.

Materials and Methods: Sixteen healthy male football players (Mean \pm SD age $=18.53 \pm 7.2$ years, Mean \pm SD body mass index $=22.8 \pm 4.4 \mathrm{~kg} / \mathrm{m}^{2}$ ) participated in a pretest-posttest study. The subjects received one session of HPL ( $808 \mathrm{~nm}, 80 \mathrm{j}, 2 \mathrm{w})$ on quadriceps muscles. The Isometric Peak Torque (IPT), Single-Leg Hop Test (SLHT), and Y-balance Test (YBT) were measured at baseline and immediately after HPL. For statistical analysis, we used the paired sample $t$ test.

Results: Immediately after HPL, the IPT ( $\mathrm{P}=0.001)$, SLHT ( $\mathrm{P}=0.02)$, and YBT scores $(\mathrm{P}=0.001)$ significantly increased.

Conclusion: The results of our study showed that immediate application of one session of HPL can improve IPT as well as functional tests. Although the sessions of laser application and assessment were limited and the sample size was small, it seems that HPL could improve muscle performance. Therefore, further research is warranted with large sample size and follow-up. 


\section{Introduction}

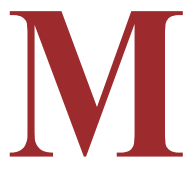

uscle performance refers to the capacity of skeletal muscle to produce force for a specific physical activity or exercise [1]. Achieving optimal performance is the desire of all athletes at all levels of sport [2]. Athlete's performance depends on several factors, including the ability to produce and maintain a high level of physical, technical, mental, and decision-making skills during the competition [3].

Researchers have shown that phototherapy can activate muscle bioenergy and therefore, can affect the mechanical function of this tissue during exercise [4]. Previous studies have provided evidence for the application of laser to increase blood circulation in the irradiated tissue, increasing tissue oxygenation. increasing circulation and oxygen, thereby improving the overall ability of the muscle function. An increase in oxygen delivery to the activating muscle will also lead to enhanced Adenosine Triphosphate (ATP) production via aerobic respiration $[5,6]$.

In recent decades, studies on animal [7-9] and human models [1, 10-14] have suggested that phototherapy, especially low power laser therapy can improve muscle performance before exercise [15-20].

The use of high power lasers has recently become common in rehabilitation. As an advantage, a High Power Laser (HPL) has greater penetration depth than a Low Power Laser (LPL) so that HPL can stimulate larger and deeper surfaces in a shorter time [21]. Therefore, it can be used for a short time before the match.

To the best of our knowledge, despite numerous studies about the effect of low power laser therapy on muscle performance [4, 22-26], only two studies about the effects of HPL on muscle performance in untrained participants were performed with contradictory results [2, 27]. Better performance has always been the focus of athletes so that one-hundredth of a second can make a difference between winning and losing [10]. Because of the mentioned advantages for HPL, this study aimed to investigate the effect of HPL on quadriceps muscle performance in male football players.

\section{Materials and Methods}

\section{Study design}

The study was conducted on healthy male football players with a single-group, pretest-posttest design. This study was in accordance with the principles of the Declaration of Helsinki, and the Ethics Committee of Tehran University of Medical Sciences approved the study protocol. All participants signed a consent form before entering the study. The flowchart of selecting participants for the current study was shown in Figure 1.

\section{Study participants}

Sixteen football players, aged 18-55 years, participated in this study. All participants were referred from the Tehran Resistance Football Club in April 2020. Healthy male semi-professional and professional football players were included in this study. The exclusion criteria included a history of musculoskeletal injury to the lower extremity in the last 6 months before entering the study, the inability of performing the study protocol, and the incidence of any injury during this study. All steps of the current study were performed in the biomechanics laboratory of Tehran University of Medical Sciences.

\section{High power laser}

A near-infrared GaAlAs laser with a wavelength of 800 nm (Novin Medical Engineering, Tehran, Iran) was used immediately after baseline assessment with the probe held at $90^{\circ}$ angle and noncontact and continuous mode. The HPL parameters used were as follows: $2 \mathrm{~W}$ radiant power; $5 \mathrm{~s}$ application time in each point; $10 \mathrm{~J}$ radiant energy per point; $1 \mathrm{~cm}^{2}$ spot size; 8 points of the quadriceps muscle ( 4 points on rectus femoris; 2 points on vastus lateralis; 2 points on vast medialis). Thus the total application time was $40 \mathrm{~s}$ and the total energy applied was $80 \mathrm{~J}$. The participants and the examiner used opaque goggles for protection (Figure 2).

\section{Outcome measures}

The outcome measures were Isometric Peak Torque (IPT), Single Leg Hop Test (SLHT), and Y-balance test. All measurements were assessed at baseline (before HPL) and immediately after the intervention.

\section{Isometric peak torque}

The IPT (Newton-meters, Nm) of the quadriceps muscle was determined at one session in the mentioned order using an isokinetic dynamometer (Series 3, Biodex, USA) measure and the computer software program version 3.29 and 3.30. The dominant leg was tested. Before each test, the participants became familiar with the procedures and warmed up by performing four isometric contractions. During the test, the examiner guided the 


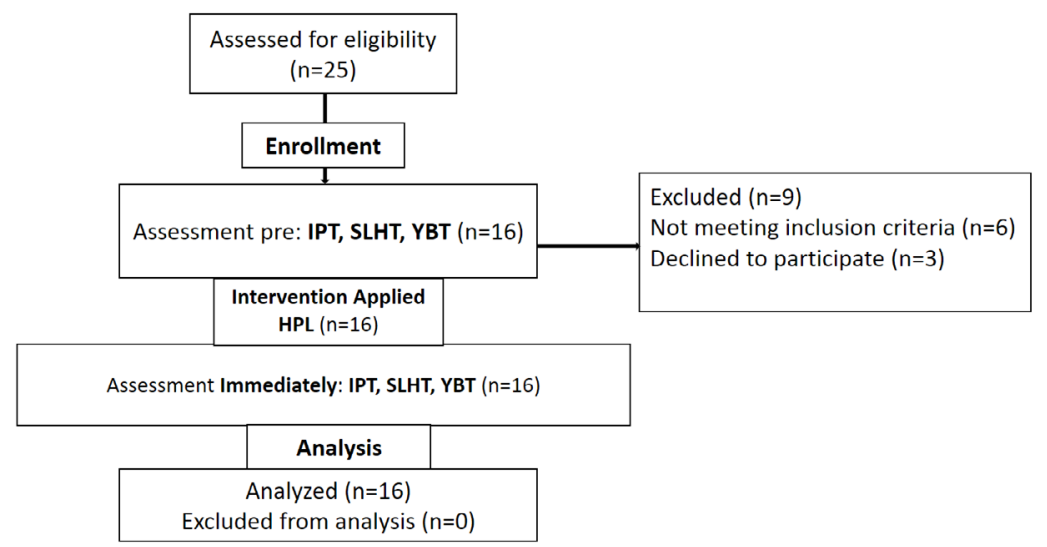

Figure 1. Flowchart of the participants' recruitment

IPT: Isometric Peak Torque; HPL: High Power Laser; SLHT: Single Leg Hop Test; YBT: Y-Balance Test

participant with standardized instructions and encouraged maximal muscle performance by verbal input.

The participants sat on the seat of the isokinetic dynamometer while the angle between trunk and hip was $100^{\circ}$. To prevent lateral movements, the hands of the participant were placed on two handles of the dynamometer that were installed on both sides and the subject's body was fixed using two straps transversely. The dominant leg was placed at $60^{\circ}$ knee flexion adjusted by device and the thigh was fixed using the strap on it. The dynamometer axis was aligned with the axis of the knee which was anatomically placed $2.5 \mathrm{~cm}$ above the head of the fibula. After that, the participant was asked to perform a Maximum Voluntary Isometric Contraction (MVIC) of the quadriceps muscle to extend the knee. The MVIC was measured at $60^{\circ}$ knee flexion.

Three trials with $5 \mathrm{~s}$ isometric contraction of the quadriceps muscle were recorded with a 30 -s rest between each trial; then, the average of them was calculated for the analysis. To avoid sub-maximal performance or outliers, the test was redone or data discarded if the coefficient of variation exceeded $10 \%$ for knee [28].

\section{Single leg hop test}

Single Leg Hop Test (SLHT) is used to evaluate the functional performance of the lower extremity that its reliability was reported by Bloqla et al. [29]. At first, the participant stood on the dominant leg with his toes behind a line marked on the floor. Then the participant hops forward as far as possible. After that, the distance from the starting point to the back of the heel was measured in centimeters [29]. The test was repeated 3 times with $9 \mathrm{~s}$ rest between each trial. The maximum distance was recorded for further analysis.

\section{Y-balance test}

The Y-balance Test (YBT) is a reliable method to assess dynamic balance in healthy people [30]. The participant was asked to stand on the dominant leg while reaching out in 3 different directions with the other lower extremity as far as possible. They are anterior, posteromedial, and posterolateral. The YBT was repeated three times in each direction then the maximum distance was recorded in centimeters. the average maximum distance in three directions was recorded as the total score for further analysis [31].

\section{Statistical analysis}

The obtained data were analyzed in SPSS, v. 16. The Kolmogorov- Smirnov (K-S) test of normality was used to assess the homogeneity of the variables. The data of this study were presented as Mean \pm SD. Paired samples $t$ test was used to compare data before and after the intervention. The level of significance was considered at $\mathrm{P}<0.05$.
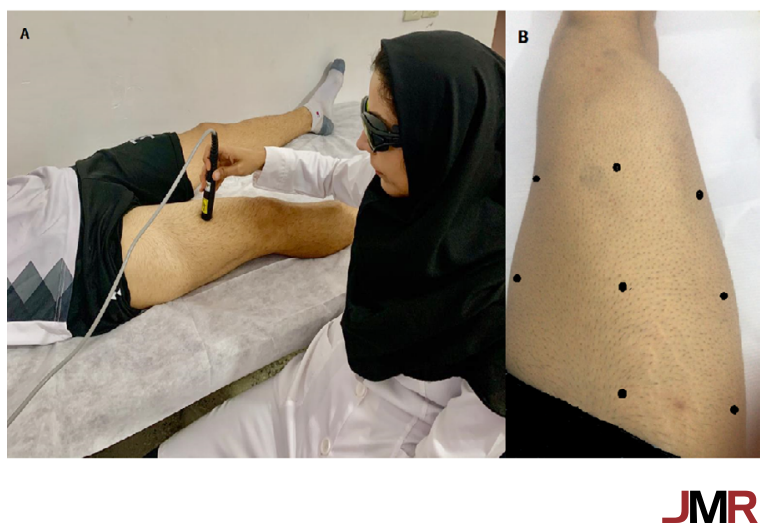

Figure 2. Application of high power laser (A) and sites of laser irradiation on quadriceps for the participants (B) 
Table 1. Descriptive statistics for all outcome measures $(n=16)$

\begin{tabular}{lcc}
\hline & Outcome Measures & Mean \pm SD \\
\hline IPT $(\mathrm{Nm})$ & Before HPL & $11.99 \pm 2.43$ \\
& Immediately after HPL & $13.48 \pm 2.02$ \\
SLHT $(\mathrm{cm})$ & Before HPL & $139.88 \pm 19.69$ \\
& Immediately after HPL & $146.75 \pm 22.12$ \\
YBT $(\mathrm{cm})$ & Before HPL & $99.33 \pm 6.72$ \\
& Immediately after HPL & $107.94 \pm 7.09$ \\
\hline
\end{tabular}

IPT: Isometric Peak Torque; Nm: Newton Meter; CM: Centimeter; HPL: High Power Laser; SLHT: Single-Leg Hop Test; YBT: Y-Balance Test

* Statistically significant: $(\mathrm{P}<0.05)$.

\section{Results}

Sixteen healthy male football players with a Mean \pm SD age of $18.53 \pm 7.2$ years and a mean Body Mass Index (BMI) of $22.8 \pm 4.4 \mathrm{~kg} / \mathrm{m}^{2}$ completed the current study. All variables were normally distributed based on the results of the K-S test $(\mathrm{P}>0.05)$. The descriptive data for all variables are shown in Table 1. Immediately after HPL, the mean values of IPT $(\mathrm{P}=0.001)$, SLHT $(\mathrm{P}=0.02)$, and total score of YBT $(\mathrm{P}=0.001)$ significantly increased.

\section{Discussion}

The objective of the current study was to evaluate the effects of HPL on the quadriceps muscle performance of healthy male football players. Based on our results immediately after HPL ( $808 \mathrm{~nm}, 2 \mathrm{~W}, 80 \mathrm{~J})$, IPT of the quadriceps muscle, SLHT, and YBT scores significantly increased. Based on our knowledge, there are only two studies on the effects of HPL on muscle performance $[27,32]$. Tiago et al. compared the effects of $\operatorname{HPL}(. / 5 \mathrm{w} /$ $\mathrm{cm} 2,980 \mathrm{~nm}$,) and LPLT (200 mW, $810 \mathrm{~nm})$ on maximum voluntary contraction, delayed-onset muscle soreness, and creatine kinase activity of quadriceps muscle in 40 healthy untrained male participants. They found that LPL has better results in all outcome measures than HPL that is conflicting with our results [32].

Several explanations may clarify our results. The method of HPL applying such as dose and radiation points may affect the results. In the present study, HPL was used as a pulse and non-contact, also the irradiation time at each point was $5 \mathrm{~s}$ to prevent the thermal effect of HPL. While Tiago et al. used a scanning method for HPL radia- tion and they reported a thermal effect. The hyperthermia due to the thermal effect of HPL lasts for several minutes that significant thermal damage may occur in biological tissues and it may have happened in Tiago et al. study.

The irradiated points in our study are more than the irradiated points of the mentioned study. Also in our study, the participants were athletes while the participants of the mentioned study were untrained people. It seems that the effects of laser irradiation are different in athletes compared to untrained subjects. Besides, there was no fatigue or exercise protocol in the present study but the eccentric contraction protocol was used in the mentioned study. Fatigue can attenuate the positive effects of HPL on muscle performance. Therefore, it seems that the ineffectiveness of HPL on muscle strength is probably due to thermal effects, fatigue, and the small number of areas in which it was applied.

In another study, Larkin et al. investigated the effects of HPL on biceps brachii (1.5 W, double wavelength of 800 and $970 \mathrm{~nm}$ ) after strenuous resistance exercise in healthy subjects [27]. In line with our findings, they reported that HPL effectively attenuated strength loss after exercise although these changes were small.

Other studies mostly have focused on the effects of HPL on pain and they indicate the positive effect of HPL on pain relief [21, 33-37].

The potential mechanism by which HPL improves muscle performance is not obvious yet. Evidence has shown that laser therapy has positive effects on the biochemical activity of muscle cells. Some of these effects are increased mitochondrial activity and synthesis of 
ATP, as well as accelerating the inflammatory process and exertion of waste product in the muscle $[38,39]$. To adequately assess the effects of laser therapy on muscle performance, future researchers should focus on the analysis of biochemical markers of muscle and fatigue.

Because studies about the effects of HPL on muscle performance are limited, more studies are needed to determine the appropriate laser parameter.

The current study has some limitations. One limitation is the lack of a control group. Also, only the immediate effects of laser therapy were investigated. So, further research is needed on the medium and long-term effects of laser therapy in other sports.

\section{Conclusion}

The results of the current study showed that immediate application of one session of the HPL on quadriceps muscle in healthy football players can significantly improve IPT, SLHT, and YBT scores. It seems that HPL can enhance muscle performance while confirming our results need more studies with larger sample size and longer follow-up.

\section{Clinical implication}

The results of this study provide that HPL has positive effects on the immediate improvement of muscle performance in healthy athletes.

\section{Ethical Considerations}

\section{Compliance with ethical guidelines}

This study was in accordance with the principles of the Declaration of Helsinki. The Ethics Committee of Tehran University of Medical Sciences approved the protocol of the study.

\section{Funding}

This study was supported and approved by the Tehran University of Medical Sciences.

\section{Authors contributions}

Conceptualization, study design: Elham Gorji, Seyed Mohsen Mir; Data analysis: Elham Gorji, Siamak Bashardoust Tajali; Interpretation of data: Kazem Malmir, Elham Gorji; Writing the original draft: All authors; Writing-review, editing: Elham Gorji, Kazem
Malmir, Siamak Bashardoust Tajali; Supervision: Seyed Mohsen Mir.

\section{Conflict of interest}

The authors declared no conflict of interest.

\section{Acknowledgements}

We also thank the Research Deputy, Tehran University of Medical Sciences (TUMS) for supporting this study.

\section{References}

[1] Vanin AA, Verhagen E, Barboza SD, Costa LOP, Leal-Junior ECP. Photobiomodulation therapy for the improvement of muscular performance and reduction of muscular fatigue associated with exercise in healthy people: A systematic review and meta-analysis. Lasers in Medical Science. 2018; 33(1):181214. [DOI:10.1007/s10103-017-2368-6] [PMID]

[2] De Marchi T, Schmitt VM, Danúbia da Silva Fabro C, da Silva LL, Sene J, Tairova O, et al. Phototherapy for improvement of performance and exercise recovery: Comparison of $3 \mathrm{com}-$ mercially available devices. Journal of Athletic Training. 2017; 52(5):429-38. [DOI:10.4085/1062-6050-52.2.09] [PMID] [PMCID]

[3] Manske RC, Davies GJ. A nonsurgical approach to examination and treatment of the patellofemoral joint, part 2: Pathology and nonsurgical management of the patellofemoral joint. Critical Reviews ${ }^{\mathrm{TM}}$ in Physical and Rehabilitation Medicine. 2003, 15(3\&4). [DOI:10.1615/CritRevPhysRehabilMed.v15.i34.50]

[4] de Brito Vieira WH, Ferraresi C, de Andrade Perez SE, Baldissera V, Parizotto NA. Effects of low-level laser therapy $(808 \mathrm{~nm})$ on isokinetic muscle performance of young women submitted to endurance training: A randomized controlled clinical trial. Lasers in Medical Science. 2012; 27(2):497-504 [DOI:10.1007/s10103-011-0984-0] [PMID]

[5] Tullberg M, Alstergren PJ, Ernberg MM. Effects of lowpower laser exposure on masseter muscle pain and microcirculation. Pain. 2003; 105(1-2):89-96. [DOI:10.1016/S03043959(03)00166-0]

[6] Silveira PCL, da Silva LA, Fraga DB, Freitas TP, Streck EL Pinho R. Evaluation of mitochondrial respiratory chain activity in muscle healing by low-level laser therapy. Journal of Photochemistry and Photobiology B: Biology. 2009; 95(2):8992. [DOI:10.1016/j.jphotobiol.2009.01.004] [PMID]

[7] Komatsu M, Kubo T, Kogure S, Matsuda Y, Watanabe K. Effects of $808 \mathrm{~nm}$ low-power laser irradiation on the muscle contraction of frog gastrocnemius. Lasers in Surgery and Medicine. 2008; 40(8):576-83. [DOI:10.1002/lsm.20665] [PMID]

[8] Ferraresi C, de Sousa MVP, Huang Y-Y, Bagnato VS, Parizotto NA, Hamblin MR. Time response of increases in ATP and muscle resistance to fatigue after low-level laser (light) therapy (LLLT) in mice. Lasers in Medical Science. 2015; 30(4):1259-67. [DOI:10.1007/s10103-015-1723-8] [PMID]

[9] Xu X, Zhao X, Liu TC-Y, Pan H. Low-intensity laser irradiation improves the mitochondrial dysfunction of $\mathrm{C} 2 \mathrm{C} 12$ induced by 
electrical stimulation. Photomedicine and Laser Surgery. 2008; 26(3):197-202. [DOI:10.1089/pho.2007.2125] [PMID]

[10] Knicker AJ, Renshaw I, Oldham ARH, Cairns SP. Interactive processes link the multiple symptoms of fatigue in sport competition. Sports Medicine. 2011; 41(4):307-28. [DOI:10.2165/11586070-000000000-00000] [PMID]

[11] Myer GD, Faigenbaum AD, Chu DA, Falkel J, Ford KR, Best TM, et al. Integrative training for children and adolescents: techniques and practices for reducing sports-related injuries and enhancing athletic performance. The Physician and Sportsmedicine. 2011; 39(1):74-84. [DOI:10.3810/ psm.2011.02.1864] [PMID]

[12] Rampinini E, Bishop D, Marcora SM, Bravo DF, Sassi R, Impellizzeri FM. Validity of simple field tests as indicators of match-related physical performance in top-level professional soccer players. International Journal of Sports Medicine. 2007; 28(3):228-35. [DOI:10.1055/s-2006-924340] [PMID]

[13] Fornell C, Johnson MD, Anderson EW, Cha J, Bryant BE. The American customer satisfaction index: nature, purpose, and findings. Journal of Marketing. 1996; 60(4):7-18. [DOI:10.1 177/002224299606000403]

[14] Aagaard P, Simonsen EB, Magnusson SP, Larsson B, Dyhre-Poulsen P. A new concept for isokinetic hamstring: quadriceps muscle strength ratio. The American Journal of Sports Medicine. 1998; 26(2):231-7. [DOI:10.1177/0363546598 0260021201] [PMID]

[15] da Silva Alves MA, Pinfildi CE, Neto LN, Lourenço RP, de Azevedo PHSM, Dourado VZ. Acute effects of low-level laser therapy on physiologic and electromyographic responses to the cardiopulmonary exercise testing in healthy untrained adults. Lasers in Medical Science. 2014; 29(6):1945-51. [DOI:10.1007/s10103-014-1595-3] [PMID]

[16] Zagatto AM, de Paula Ramos S, Nakamura FY, de Lira FS, Lopes-Martins RÁB, de Paiva Carvalho RL. Effects of low-level laser therapy on performance, inflammatory markers, and muscle damage in young water polo athletes: A double-blind, randomized, placebo-controlled study. Lasers in Medical Science. 2016; 31(3):511-21. [DOI:10.1007/s10103-016-1875-1] [PMID]

[17] Denis R, O'Brien C, Delahunt E. The effects of light emitting diode therapy following high intensity exercise. Physical Therapy in Sport. 2013; 14(2):110-5. [DOI:10.1016/j. ptsp.2012.03.014] [PMID]

[18] Machado CDSM, Casalechi HL, Vanin AA, de Azevedo JB, de Carvalho PdTC, Leal-Junior ECP. Does photobiomodulation therapy combined to static magnetic field (PBMT-sMF) promote ergogenic effects even when the non-exercised leg is irradiated? A randomized, triple-blind, placebo-controlled trial. BMC Sports Science, Medicine and Rehabilitation. 2020; 12:49. [DOI:10.21203/rs.2.19987/v1]

[19] Dellagrana RA, Rossato M, Sakugawa RL, Lazzari CD, Baroni BM, Diefenthaeler F. Dose-response effect of photobiomodulation therapy on neuromuscular economy during submaximal running. Lasers in Medical Science. 2018; 33(2):32936. [DOI:10.1007/s10103-017-2378-4] [PMID]

[20] Pinto HD, Vanin AA, Miranda EF, Tomazoni SS, Johnson DS, Albuquerque-Pontes GM, et al. Photobiomodulation therapy improves performance and accelerates recovery of high-level rugby players in field test: A randomized, crossover, double-blind, placebo-controlled clinical study. The Jour- nal of Strength \& Conditioning Research. 2016; 30(12):332938. [DOI:10.1519/JSC.0000000000001439] [PMID]

[21] Tabatabai SMR, Tajali SB, Moghadam BA, Mir SM. Effects of high-Power diode laser irradiation combined with electrical stimulation on wrist pain and function following carpal tunnel syndrome. Journal of Clinical Physiotherapy Research. 2016; 1(2):61-7. [DOI:10.22037/jcpr.v1i2.13702]

[22] Leal ECP, Lopes-Martins RÁB, Frigo L, De Marchi T, Rossi $\mathrm{RP}$, De Godoi V, et al. Effects of low-level laser therapy (LLLT) in the development of exercise-induced skeletal muscle fatigue and changes in biochemical markers related to postexercise recovery. Journal of Orthopaedic \& Sports Physical Therapy. 2010; 40(8):524-32. [DOI:10.2519/jospt.2010.3294] [PMID]

[23] Baroni BM, Junior ECPL, De Marchi T, Lopes AL, Salvador M, Vaz MA. Low level laser therapy before eccentric exercise reduces muscle damage markers in humans. European Journal of Applied Physiology. 2010; 110(4):789-96. [DOI:10.1007/ s00421-010-1562-z] [PMID]

[24] De Marchi T, Junior ECPL, Bortoli C, Tomazoni SS, LopesMartins RÁB, Salvador M. Low-level laser therapy (LLLT) in human progressive-intensity running: effects on exercise performance, skeletal muscle status, and oxidative stress. Lasers in Medical Science. 2012; 27(1):231-6. [DOI:10.1007/s10103011-0955-5] [PMID]

[25] Ferraresi C, de Brito Oliveira T, de Oliveira Zafalon L, de Menezes Reiff RB, Baldissera V, de Andrade Perez SE, et al. Effects of low level laser therapy $(808 \mathrm{~nm})$ on physical strength training in humans. Lasers in Medical Science. 2011; 26(3):349-58. [DOI:10.1007/s10103-010-0855-0] [PMID]

[26] Felismino AS, Costa EC, Aoki MS, Ferraresi C, Lemos TMdAM, de Brito Vieira WH. Effect of low-level laser therapy $(808 \mathrm{~nm})$ on markers of muscle damage: A randomized double-blind placebo-controlled trial. Lasers in Medical Science. 2014; 29(3):933-8. [DOI:10.1007/s10103-013-1430-2] [PMID]

[27] Larkin-Kaiser KA, Christou E, Tillman M, George S, Borsa PA. Near-infrared light therapy to attenuate strength loss after strenuous resistance exercise. Journal of Athletic Training. 2015; 50(1):45-50. [DOI:10.4085/1062-6050-49.3.82] [PMID] [PMCID]

[28] Baroni BM, Rodrigues R, Freire BB, de Azevedo Franke R, Geremia JM, Vaz MA. Effect of low-level laser therapy on muscle adaptation to knee extensor eccentric training. European Journal of Applied Physiology. 2015; 115(3):639-47. [DOI:10.1007/s00421-014-3055-y] [PMID]

[29] Bolgla LA, Keskula DR. Reliability of lower extremity functional performance tests. Journal of Orthopaedic \& Sports Physical Therapy. 1997; 26(3):138-42. [DOI:10.2519/ jospt.1997.26.3.138] [PMID]

[30] Linek P, Sikora D, Wolny T, Saulicz E. Reliability and number of trials of Y Balance Test in adolescent athletes. Musculoskeletal Science and Practice. 2017; 31:72-5. [DOI:10.1016/j. msksp.2017.03.011] [PMID]

[31] Shaffer SW, Teyhen DS, Lorenson CL, Warren RL, Koreerat $\mathrm{CM}$, Straseske CA, et al. Y-balance test: A reliability study involving multiple raters. Military Medicine. 2013; 178(11):126470. [DOI:10.7205/MILMED-D-13-00222] [PMID]

[32] Antonialli FC, De Marchi T, Tomazoni SS, Vanin AA, dos Santos Grandinetti V, de Paiva PRV, et al. Phototherapy in skeletal muscle performance and recovery after exercise: Effect of combination of super-pulsed laser and light-emit- 
ting diodes. Lasers in Medical Science. 2014; 29(6):1967-76. [DOI:10.1007/s10103-014-1611-7] [PMID]

[33] Nouri F, Raeissadat SA, Eliaspour D, Rayegani SM, Rahimi MS, Movahedi B. Efficacy of high-power laser in alleviating pain and improving function of patients with patellofemoral pain syndrome: A single-blind randomized controlled trial. Journal of Lasers in Medical Sciences. 2019; 10(1):37-43. [DOI:10.15171/jlms.2019.06] [PMID] [PMCID]

[34] Fiore P, Panza F, Cassatella G, Russo A, Frisardi V, Solfrizzi $\mathrm{V}$, et al. Short-term effects of high-intensity laser therapy versus ultrasound therapy in the treatment of low back pain: A randomized controlled trial. European Journal of Physical and Rehabilitation Medicine. 2011; 47(3):367-73. [PMID]

[35] Alayat MSM, Atya AM, Ali MME, Shosha TM. Long-term effect of high-intensity laser therapy in the treatment of patients with chronic low back pain: A randomized blinded placebo-controlled trial. Lasers in Medical Science. 2014; 29(3):1065-73. [DOI:10.1007/s10103-013-1472-5] [PMID]

[36] Angelova A, Ilieva EM. Effectiveness of high intensity laser therapy for reduction of pain in knee osteoarthritis. Pain Research and Management. 2016; 2016:9163618. [DOI:10.1155/2016/9163618] [PMID] [PMCID]

[37] Nikolis A, Grimard D, Pesant Y, Scapagnini G, Vézina D. A prospective case series evaluating the safety and efficacy of the Klox BioPhotonic System in venous leg ulcers. Dovepress. 2016; 3:101-11. https://www.dovepress.com/a-prospectivecase-series-evaluating-the-safety-and-efficacy-of-the-kl-peerreviewed-article-CWCMR\#

[38] Huang Y-Y, Chen AC-H, Carroll JD, Hamblin MR. Biphasic dose response in low level light therapy. Dose-Response: A Publication of International Hormesis Society. 2009; 7(4):358-83. [DOI:10.2203/dose-response.09-027.Hamblin] [PMID] [PMCID]

[39] Alexandratou E, Yova D, Handris P, Kletsas D, Loukas S. Human fibroblast alterations induced by low power laser irradiation at the single cell level using confocal microscopy. Photochemical \& Photobiological Sciences. 2002; 1(8):547-52. [DOI:10.1039/b110213n] [PMID] 
This Page Intentionally Left Blank 